\title{
МОДЕЛЬ ЦЕНТРАЛИЗОВАННОГО ОКАЗАНИЯ ЮРИДИЧЕСКИХ УСЛУГ (КАНАДСКИЕ УРОКИ ДЛЯ РОССИИ)
}

Аннотация: Статья посвящена особенностям организации и функционирования Министерства юстиции Канады. Рассматриваются его функции, стандарты качества оказания юридических услуг и консультаций, механизмы управления правовыми рисками в правительстве Канады. Выявляются преимущества такой модели, доказавшей свою эффрективность на протяжении более 50 лет, для системы государственного управления в Канаде. Анализируется опыт проведения в 2006 - 2013 г2. в администрации Липецкой области эксперимента по адаптации в его деятельности канадской модели централизованного предоставления юридических услуг. На основе проведенного автором социологического исследования и статистических данных деятельности правового управления администрации Липецкой области делается вывод об успешности данного эксперимента. По мнению автора, целесообразно изучить возможность введения подобной модели в других субъектах Российской Федерациии и в деятельности Правительства Российской Федерации. Для этого необходимо разработать индикаторы (показатели) качества юридических услуг и консультаций в системе государственного управления Российской Федерации, создать механизмы измерения эффективности работы юристов-государственных служащих.

Ключевые слова: Министерство юстиции Канады, единая правовая позиция, эффективность государственных услуг, оценка качества, централизация, адаптация зарубежного опыта, эксперимент, объективность, профессионализм, критерии удовлетворенности.

DOI: $10.7256 / 1994-1471.2014 .6 .11206$

$B$ декабре 2013 года Председатель Правительства Российской Федерации Дмитрий Медведев обратил внимание на обострившуюся проблему эффективности юридического управления. По его мнению, сейчас «важнейший вопрос: как избежать в результате прохождения правовым актом многоступенчатых процедур «юридического искажения» его политического, экономического или социального содержания и, что более важно, его конституционного смысла?.. Таким образом, ключевой задачей сегодня становится модификация юридических технологий в системе федеральной исполнительной власти - от подготовки инициативы по принятию правового акта до мониторинга его применения... При этом важно сочетать централизацию и децентрализацию юридического управления (выделено мной - С.К.) ${ }^{1}$.

Медведев Д. А. 20 лет: путь к осознанию права // Российская газета. 2013. 11 декабря. Федеральный выпуск 6255 (279).

Rg.ru; <http://www.rg.ru/2013/12/10/medvedev.html> (последнее посещение - 10.02.2014).
В этой связи стоит обратить внимание на положительный опыт такого управления, который есть в других странах.

Министерство юстиции Канады было образовано в 1868 году. Его основной обязанностью было предоставление юридических услуг правительству Канады ${ }^{2}$. С развитием государства и общества появлялись новые вызовы, которые требовали правовой оценки. Так, различные министерства и ведомства правительства Канады постепенно создали свои собственные юридические службы либо обращались к услугам частных юристов. В сентябре 1960 года оказалось, что значительное количество правовой работы для федеральных ведомств осуществляется без прямого участия Министерства юстиции. Была создана королевская комиссия

\footnotetext{
2 An Act respecting the Department of Justice, adopted during the first session of the Parliament of the Dominion of Canada and assented to on 22 May 1868 (31 Vic., c.39). Archivescanada.ca; <http://www.archivescanada.ca/english/ search/ItemDisplay.asp?sessionKey=1143825756048_206_1 91_57_199\&l $=0 \& \mathrm{lvl}=0 \& \mathrm{v}=0 \&$ coll $=0 \& \mathrm{itm}=257613 \& \mathrm{rt}=1 \& \mathrm{~b}$ ill $=1>$ (последнее посещение - 10.02.2014).
}

(C) Кабышев Сергей Владимирович

* Кандидат юридических наук, доцент кафедры конституционного и муниципального права,

Московский государственный юридический университет имени О.Е. Кутафина (МГЮА)

[svkabyshev@gmail.com]

123995, Россия, г. Москва, Садовая-Кудринская ул., д. 9. 
(Glassco Commission), которой было поручено проанализировать работу правительства Канады и сделать предложения по повышению его эффективности и улучшению качества предоставляемых обществу услуг. Комиссия, рассмотрев эти вопросы, пришла к выводу, что система организации государственной юридической службы неэффективна, более чем 85 процентов юридических услуг, оказываемых правительством Канады, не находятся в компетенции Министерства юстиции. Небольшие группы юристов (иногда это был вообще один юрист), имевшие обязательства перед своими клиентами-министерствами как работодателями, не обладали достаточной степенью независимости и профессионального кругозора. Это приводило к долгим межведомственным спорам. Было предложено, чтобы все юридические услуги (с некоторыми исключениями ${ }^{3}$ ) были сгруппированы в Министерстве юстиции, с тем чтобы обеспечить проведение единой правовой политики ${ }^{4}$. Предложения комиссии Гласско были одобрены правительством и начали реализовываться 5 .

Интеграция всех юристов, находящихся на государственной службе 6 в Министерстве юстиции Канады, произошла в 1966 году. В период с 1961 года по настоящее время количество сотрудников Министерства юстиции Канады возросло с 42-х до 5000.

Такая интеграция позволила:

- повысить качество и своевременность правовых услуг;

- обеспечить объективность и независимость (юристы принимаются на службу министром юстиции и не зависят карьерно от министров, с которыми они работают);

- создать возможности карьерного роста для юристов (предоставить более интересную многоплановую работу, более высокую заработную плату);

- ослабить тенденцию к выдаче заключений, носивших излишне академический характер, поскольку постоянная ротация

\footnotetext{
Исключения связаны с вопросами государствен ной тайны в деятельности Министерств обороны, внутренних и иностранных дел. В настоящее время юристы Министерства юстиции Канады работают в 50 отраслевых министерствах и ведомствах федерального правительства, включая государственные (королевские) корпорации.

4 Report of the Royal Commission on Government Organization, Volume I: Management of the Public Service. Ottawa: Queen's Printer, 1962. P. 19.

McLeod T. H. Glassco Commission Report // Canadian Public Administration. 1963. Volume 6, Issue 4. P. 386-406.

6 Важно отметить, что юристы парламента не являются государственными служащими. В Канаде парламентская служба самостоятельна.
}

обеспечивала крепкую связь с реальным положением дел (как правило, юрист работает в отраслевом министерстве не более трех лет);

- добиться последовательности и согласованности всех юридических заключений различных государственных органов;

- оптимизировать затраты.

Монополия государственной юридической службы позволяет Министерству юстиции «говорить одним голосом» со всеми органами государственной власти и их подразделениями по всей стране. При этом подавляющее большинство юристов, работающих в Министерстве юстиции, находятся вовсе не в здании Минюста. Их рабочие места непосредственно в отраслевых министерствах-клиентах. Кроме того, в региональных представительствах Министерства работают около 2000 человек, которые оказывают правовые услуги чиновникам федеральных министерств за пределами столицы. Центральный аппарат Министерства юстиции состоит из нескольких подразделений, среди которых департаменты: Хартии прав и свобод, административного права, конституционного права, международного права, права коренных народностей, официальных языков, вопросов защиты информации и неприкосновенности личной сферы жизни и др. ${ }^{7}$

Содержательным преимуществом централизации юридической службы является то обстоятельство, что создаются условия для формирования аргументированной правовой позиции. Известно, что где два юриста, там три мнения. Позиции отдельных юристов могут не совпадать. Однако весьма непродуктивно, когда министры приходят на заседания Кабинета с заключениями юристов, противоречащих друг другу. Министр юстиции должен до заседания снять все вопросы, выступив арбитром в возникшем споре, и представить Кабинету единую согласованную правовую позицию.

В конституционно-правовой системе Канады министр юстиции выступает в роли советника по юридическим вопросам всего правительства.

Министр юстиции осуществляет контроль за тем, чтобы государственное управление осуществлялось в соответствии с Конституцией Канады, а также за соответствием разрабатываемых законопроектов и положений Канадской Хартии прав и свобод 8 .

Justice.gc.ca; Organization of the Department of Justice $<$ http://www.justice.gc.ca/eng/abt-apd/org.html> (последнее посещение - 10.02.2014).

8 Laws-lois.justice.gc.ca; Department of Justice Act, s.4 (R.S.C., 1985, c. J-2) <http://laws-lois.justice.gc.ca/eng/ acts/J-2/> (последнее посещение - 10.02.2014). 
Заслуживает внимания организация законопроектной деятельности в Канаде. Все инициативы, которые исходят от исполнительной власти любого уровня, оформляются в виде текста законопроекта сотрудниками Министерства юстиции Канады. В Министерстве юстиции создан отдел разработчиков законопроектов (около 100 человек), которые вместе с юристами, работающими в отраслевых министерствах, осуществляют подготовку законопроектов. Разработчики законопроектов вне политики, они профессионалы и должны составлять документы на двух государственных языках Канады, на основе правил юридической техники, содержащихся в разработанных Министерством юстиции Канады руководствах по составлению законопроектов и актов делегированного законодательства 9 . Министерство юстиции Канады организовало внутреннюю базовую программу подготовки по составлению законопроектов для своих сотрудников. Она ориентирована на развитие профессиональных навыков разработчиков законопроектов ${ }^{10}$. Таким образом, происходит профессионализация законотворческого процесса, что позволяет значительно повысить качество принимаемых законов и подзаконных актов, а также избежать противоречий при их применении ${ }^{11}$.

Канадская система государственного управления отличается высокой степенью профессионализации и независимости от политических процессов. Только министр является политической фигурой, назначаемой лидером победившей на выборах партии. Остальные сотрудники Министерства являются карьерными профессиональными работниками, которые не уходят в отставку вместе с членами правительства. Руководит работой Министерства заместитель министра. Он и несет ответственность за эффективность работы всех сотрудников $^{12}$. Были разработаны стандарты

Законотворчество в Канаде / отв. ред. С. В. Кабышев. M., 2006. C. 3-223.

10 Кабышев С. В. Обучение юридической технике в Канаде // Юридическая техника. 2009. № 3. С. 175-177.

11 По среднестатистическим данным 95\% законопроектов, подготовленных министерством юстиции Канады и внесенных в парламент правительством, становятся законами. Оставшиеся 5\% законопроектов, предложенные оппозиционной партией либо независимыми депутатами, дорабатываются парламентскими юристами.

Parl.gc.ca; <http://www.parl.gc.ca/LEGISinfo/LAAG. aspx LLanguage $=\mathrm{E} \& M o d e=1>$ (последнее посещение 10.02.2014).

12 Bourgault J., Dunn C. Deputy Ministers in Canada: Comparative and Jurisdictional Perspectives. University of Toronto Press, 2014. P. 426-428. качества предоставления юридических услуг (доступность, ясность, отзывчивость, своевременность, полезность и т.п.) правительству ${ }^{13}$. Заместитель министра юстиции с их помощью планирует и управляет работой своих сотрудников ${ }^{14}$, используя механизмы обратной связи. Для этого проводятся исследования степени удовлетворенности клиентов оказанными юридическими услугами министерством, которые размещаются на WEB-сайте Минюста Канады и учитываются при служебной аттестации сотрудников ${ }^{15}$.

Исследования степени удовлетворенности клиентов являются ключевым элементом измерения эффективности работы государственных служащих Канады, позволяя определить направления совершенствования качества услуг ${ }^{16}$.

Организационные преимущества такой модели позволяют использовать единые стандарты подбора и повышения квалификации кадров, большую прозрачность и справедливость при оплате услуг юристов. Необходимо пояснить, что министерствоклиент направляет в Совет Казначейства Канады и Минюст данные о трудозатратах юристов, которые его обслуживают. Эти данные проверяет Минюст и либо подтверждает их, либо нет, что-то корректируя. Совет Казначейства регулярно проверяет обоснованность оплаты труда юристов, работающих в министерствах ${ }^{17}$.

Канадский опыт уникален. Начавшись в 60-е годы прошлого века как эксперимент, он уже 50 лет подтверждает правоту его инициаторов, что централизация юридических услуг в рамках Министерства юстиции наиболее эф-

13 Canada.justice.gc.ca; Service Standards for the Provision of Legal Services in Government <http://canada.justice. gc.ca/eng/dept-min/service.html> (последнее посещение 10.02.2014).

14 Tbs-sct.gc.ca; Policy on Legal Assistance and Indemnification <http://www.tbs-sct.gc.ca/pol/doc-eng. aspx?section=text\&id=13937> (последнее посещение 10.02.2014).

15 Justice.gc.ca; Department of Justice Canada Client Feedback Survey <http://www.justice.gc.ca/eng/rp-pr/cp$\mathrm{pm} / \mathrm{dpr}-\mathrm{rr} / 2012 / \mathrm{sur} / \mathrm{toc}-\mathrm{tdm} . \mathrm{html}>$ (последнее посещение - 10.02.2014)

16 Paul G. Thomas. Performance Measurement and Management in the Public Sector // Optimum: The Journal of Public Sector Management. University of Ottawa. Vol. 35, Issue 2, July 2005, Page 16.

Optimumonline.ca; <http://www.optimumonline.ca/article. phtml?e=fjtcgvty\&id=225> (последнее посещение 10.02.2014).

17 Laws-lois.justice.gc.ca; Financial Administration Act (R.S.C., 1985, c. F-11) <http://laws-lois.justice.gc.ca/ eng/acts/F-11/index.html> (последнее посещение 10.02.2014). 
фективный способ обеспечения деятельности канадского правительства ${ }^{18}$.

В 2005 - 2009 годах в рамках реализации российско-канадской программы «Содействие реформированию государственного управления в Российской Федерации» представители Министерства юстиции Канады провели обучающие семинары для сотрудников правовых управлений как федеральных министерств и ведомств, так и администраций всех субъектов Российской Федерации, и организовали для них стажировки в Канаде для изучения опыта организации юридической службы ${ }^{19}$.

Автором в 2005 г. было проведено социологическое исследование путем анкетирования руководителей исполнительных органов специальной компетенции, юристов правового управления субъектов Российской Федерации (всего 460 человек) для выявления мнения практических работников о путях повышения эффективности своей работы.

Было установлено, что организация юридических служб в субъектах РФ имеет общие принципы: наличие правовых управлений, обеспечивающих деятельность власти, а также юристов в органах или структурных подразделениях, сформированных по отраслевому принципу.

При этом на юристов правовых управлений ложится основная тяжесть ведения этой работы.

По данным Тамбовской области, из 1,5 тысяч поступивших в правовое управление из органов специальной компетенции проектов постановлений администрации в 2005 г. каждый второй документ возвращается на доработку в органы специальной компетенции (подразделения). По среднестатистическим данным Липецкой области, один юрист правового управления в день принимает участие в двух судебных заседаниях, проводит экспертизу восьми документов, принимает участие в трех заседаниях различных рабочих групп, комиссий, комитетов.

Анкетируемые выделяют общие негативные черты существующей организации юридических служб:

1. Превалирование принципа субъективной целесообразности над принципом законности: руководители органов (подразделений), стремясь в первую очередь решить

\footnotetext{
18 Oag-bvg.gc.ca;Доклад Генерального аудитора Канады «Об эффективности предоставления юридических услуг Министерством юстиции Канады» <http://www.oagbvg.gc.ca/internet/English/parl_oag_200705_05_e_17480. $\mathrm{html}>$ (последнее посещение - 10.02.2014).

19 Formulaprava.ru; Сайт программы <www. formulaprava.ru> (последнее посещение - 10.02.2014).
}

поставленную задачу, не всегда выбирают для ее решения в полной мере соответствующий законодательству путь, не прислушиваются в должной мере к мнению юристов.

2. Служебная зависимость юристов органов специальной компетенции (подразделений) от руководителей этих органов приводит к тому, что юристы, опасаясь неприятностей по службе, не настаивают в должной степени на соответствии документов законодательству.

3. Недостаточное качество юридической подготовки документов юристами органов специальной компетенции (подразделений), их расчет на то, что необходимая работа будет проведена юристами правовых управлений, на которое и ляжет ответственность за качество документа.

4. Дублирование правового анализа одних и тех же документов юристами, находящимися в органах специальной компетенции (подразделениях) и правовых управлениях.

5. Нечеткое разделение обязанностей между юристами органов специальной компетенции (подразделений) и правовых управлений, что во многом и приводит к указанным выше недостаткам в юридическом обеспечении работы исполнительной власти в целом.

Проведенный анализ позволяет сделать вывод о том, что многие из указанных негативных явлений представляют собой следствие отсутствия единого подхода к организации и деятельности правовых служб.

Большинство опрошенных (83\%) выразили заинтересованность в адаптации канадской модели централизации в практике правового обеспечения своей деятельности. Но только начальник правового управления администрации Липецкой области Галина Алексеевна Пивовар убедила своего руководителя отважиться на такой эксперимент.

30 октября 2006 года Глава администрации Липецкой области издал постановление № 1051-р «0 централизации правового обеспечения главы администрации области, администрации области, органов исполнительной власти Липецкой области» ${ }^{20}$, согласно которому создана единая юридическая служба путем объединения в структуре правового управления администрации области всех существующих юридических служб исполнительных органов власти специальной компетенции.

20 Admlip.ru; Администрация Липецкой области $<$ http://admlip.ru/blind/authorities/struktury/pravovoeupravlenie-administratsii-oblasti/> (последнее посещение 10.02.2014). 
Было предусмотрено, что при создании новых отраслевых исполнительных органов единицы юристов вводятся в штат правового управления администрации области.

Штатная численность правового управления администрации области составила 53 человека, было создано 8 отделов:

- отдел правового обеспечения главы администрации области и администрации области, судебной и договорной работы; отдел законотворческой деятельности; отдел по ведению Регистра муниципальных нормативных правовых актов;

отдел правового обеспечения в социальной сфере;

- отдел правового обеспечения в сфере финансов, дорог, транспорта, энергетики, тарифов и ЖКХ;

- отдел правового обеспечения в сфере сельского хозяйства, ветеринарии, экологии;

- отдел правового обеспечения в сфере госзаказа и контрольных органов;

- отдел правового обеспечения в сфере имущественных, земельных отношений и строительства.

Были утверждены должностные регламенты государственных гражданских служащих Липецкой области, замещающих соответствующие должности в правовом управлении администрации Липецкой области, в соответствии с которыми избрана схема работы, заключающаяся в том, что юристы, находясь в штате правового управления, непосредственно осуществляют правовое обеспечение исполнительных органов власти специальной компетенции в самом органе. Фактическое место работы и их функциональные обязанности остались неизменными. При этом они вышли из подчинения руководителя исполнительного органа власти специальной компетенции. Так, часть сотрудников управления была закреплена за следующими исполнительными органами государственной власти Липецкой области:

- Управлением образования и науки - 1 единица;

- Управлением энергетики, тарифов и жилищно-коммунального хозяйства - 2 единицы;

- Управлением потребительского рынка, управлением по ценам и контролю в сфере размещения государственных заказов - 3 единицы;

- Управлением имущественных и земельных отношений - 4 единицы;

- Управлением экологии и природных ресурсов - 1 единица;

- Управлением по размещению госзаказа Липецкой области - 2 единицы;
- Управлением ветеринарии - 1 единица;

- Управлением здравоохранения - 1 единица;

- Управлением сельского хозяйства - 3 единицы;

- Управлением социальной защиты населения - 2 единицы;

- Управлением финансов - 2 единицы;

- Управлением строительства и архитектуры - 1 единица;

- Инспекцией государственного строительного надзора - 1 единица;

- Государственной жилищной инспекцией 2 единицы.

Семилетний опыт реализации канадской модели организации и функционирования правового управления администрации Липецкой области и социологические исследования автора по результатам эксперимента (в 2013 г.) позволяют сделать следующие выводы:

Юристы, занимающиеся правовым обеспечением деятельности отраслевых органов исполнительной власти, почувствовали независимость, в результате чего:

- их юридические заключения стали более качественными и объективными;

- они вовлечены в процесс разработки правовых актов с первых дней, что положительно сказалось на соблюдении установленных сроков и выполнении плана нормотворческой деятельности;

- они получили возможность повышать свою квалификацию на должном уровне, использовать правовой опыт других в результате обмена им на проводимых конференциях, совещаниях, тренингах.

Появились реальные возможности:

- карьерного роста;

- более эффективного перераспределения функций между сотрудниками юридической службы;

- формирования единой правовой позиции;

- эффективного обобщения судебной практики.

Это способствовало тому, что, например, в 2008 - 2012 годах ни один нормативный правовой акт администрации Липецкой области не был оспорен в суде. По итогам работы за эти годы прокуратурой Липецкой области ни на один нормативный правовой акт администрации Липецкой области не было внесено протестов или представлений.

Все участники социологического исследования отмечают еще один существенный результат внедрения канадской модели - повышение престижа профессии юриста, уважительное отношение руководства к мнению эксперта правоведа, невозможность принятия управленческого решения без положительного мнения юриста. 
По их мнению, нельзя утверждать, что за этот период работа доведена до совершенства, но каждый год работы подтверждает, что централизация юридической службы позволяет обеспечивать правовые услуги высокого качества и организовать работу юридической службы как единый, четкий, отлаженный механизм.
Возможность адаптации элементов канадской модели централизованного юридического управления изучается в других субъектах Российской Федерации ${ }^{21}$.

По нашему мнению, целесообразно обратить внимание на канадскую модель централизованного юридического управления и на федеральном уровне.

\section{Библиография:}

1. Кабышев С. В. Обучение юридической технике в Канаде // Юридическая техника. №3. C. $175-177$.

2. Законотворчество в Канаде / отв. ред. С. В. Кабышев. М., 2006.

3. Медведев Д. А. 20 лет: путь к осознанию права // Российская газета. 2013.11 декабря. Федеральный выпуск - 6255 (279).

4. Савин В. И. Механизмы координации деятельности юридических служб субъектов РФ // Права и свободы человека и гражданина: Актуальные проблемы науки и практики: сборник материалов I Международной научно-практической конференции. - Орел: ОРАГС, 2009. C. $125-129$.

5. Bourgault J., Dunn C. Deputy Ministers in Canada: Comparative and Jurisdictional Perspectives. University of Toronto Press, 2014. P. 426-428.

6. McLeod T. H. Glassco Commission Report// Canadian Public Administration. 1963. Volume 6, Issue 4. P. 386-406.

7. Paul G. Thomas. Performance Measurement and Management in the Public Sector // Optimum: The Journal of Public Sector Management. University of Ottawa. Vol. 35, Issue 2, July 2005, Page 16. References (transliteration).

\section{References:}

1. Kabyshev S. V. Obuchenie yuridicheskoi tekhnike v Kanade // Yuridicheskaya tekhnika. №3. C. 175177.

2. Zakonotvorchestvo v Kanade / otv. red. S. V. Kabyshev. M., 2006.

3. Medvedev D. A. 20 let: put' k osoznaniyu prava // Rossiiskaya gazeta. 2013.11 dekabrya. Federal'nyi vypusk - 6255 (279).

4. Savin V. I. Mekhanizmy koordinatsii deyatel'nosti yuridicheskikh sluzhb sub"ektov RF // Prava i svobody cheloveka i grazhdanina: Aktual'nye problemy nauki i praktiki: sbornik materialov I Mezhdunarodnoi nauchno-prakticheskoi konferentsii. - Orel: ORAGS, 2009. - S. 125-129.

5. Bourgault J., Dunn C. Deputy Ministers in Canada: Comparative and Jurisdictional Perspectives. University of Toronto Press, 2014. P. 426-428.

6. McLeod T. H. Glassco Commission Report // Canadian Public Administration. 1963. Volume 6, Issue 4. P. 386-406.

7. Paul G. Thomas. Performance Measurement and Management in the Public Sector // Optimum: The Journal of Public Sector Management. University of Ottawa. Vol. 35, Issue 2, July 2005, Page 16. References (transliteration).

21 Савин В. И. Механизмы координации деятельности юридических служб субъектов РФ // Права и свободы человека и гражданина: Актуальные проблемы науки и практики: сборник материалов I Международной научно-практической конференции. - Орел: ОРАГС, 2009. C. $125-129$. 